\title{
EMPODERAMENTO FEMININO E A FORMAÇÃO CIDADÃ PARA A EMANCIPAÇÃO DA MULHER
}

\author{
EMPODERAMIENTO DE LAS MUJERES Y CAPACITACIÓN CIUDADANA PARA LA \\ EMANCIPACIÓN DE LAS MUJERES
}

\author{
WOMEN EMPOWERMENT AND CITIZEN TRAINING FOR WOMEN'S \\ EMANCIPATION
}

\author{
Solange Aparecida de Souza MONTEIRO ${ }^{1}$
}

RESUMO: A partir de programas, projetos e serviços direcionados às mulheres em situação de vulnerabilidade social, interessadas em qualificar-se profissionalmente, entendendo ser mais uma função da escola, como elaboradora de propostas que colaborem com a emancipação do sujeito coletivo. Este artigo tem como proposta refletir sobre a promoção de atividades de igualdade de direitos entre homens e mulheres e as condições para que as mulheres conquistem autonomia, uma vez que são demandas urgentes em uma sociedade mais igualitária e desenvolvida econômica, social e culturalmente. Neste sentido, faz-se necessário verificar quais as oportunidades foram e estão sendo oferecidas para a educação e de qualificação profissional para as mulheres que, ao longo de suas trajetórias, não tiveram acesso a uma formação suficiente para garantir boas condições de vida.

PALAVRAS-CHAVE: Mulher. Emancipação. Empoderamento. Qualificação profissional.

RESUMEN: Desde programas, proyectos y servicios dirigidos a mujeres en situaciones de vulnerabilidad social, interesados en calificar profesionalmente, entendiendo ser más una función de la escuela, como elaborador de propuestas que colaboran con el La emancipación del sujeto colectivo. Este artículo propone reflexionar sobre la promoción de las actividades de igualdad de derechos entre hombres y mujeres y las condiciones para que las mujeres conquisten la autonomía, ya que son demandas urgentes en una sociedad más igualitaria y desarrollada Económica, social y culturalmente. En este sentido, es necesario verificar qué oportunidades han sido y se están ofreciendo para la educación y la cualificación profesional para las mujeres que, a lo largo de sus trayectorias, no han tenido acceso a la formación suficiente para asegurar el buen Condiciones de vida.

PALABRAS CLAVE: Mujer. Emancipación. Empoderamiento. Cualificación profesional.

ABSTRACT: From programs, projects and services aimed at women in situations of social vulnerability, interested in qualifying professionally, understanding being more a function of the school, as an elaborator of proposals that collaborate with the The emancipation of the

\footnotetext{
${ }^{1}$ Instituto Federal de São Paulo (IFSP), Araraquara - SP - Brasil. Pedadoga. Mestra em Processos de Ensino, Gestão e Inovação pela Universidade de Araraquara - UNIARA (2018). Membro dos núcleos: -Núcleo de Gêneros e Sexualidade do IFSP (NUGS); Núcleo de Apoio às Pessoas com Necessidades Educacionais Específicas (NAPNE). ORCID: <http://orcid.org/0000-0002-1640-0266>. E-mail: solmonteiro@ifsp.edu.br

RPGE- Revista on line de Política e Gestão Educacional, Araraquara, v. 22, n. 3, p. 1182-1197, set./dez., 2018. E-ISSN:1519-9029. DOI: $10.22633 /$ rpge.v22i3.12018 
collective subject. This article proposes to reflect on the promotion of equal rights activities between men and women and the conditions for women to conquer autonomy, since they are urgent demands in a more egalitarian and developed society Economically, socially and culturally. In this sense, it is necessary to verify what opportunities have been and are being offered for education and professional qualification for women who, throughout their trajectories, have not had access to sufficient training to ensure good Living conditions.

KEYWORDS: Woman. Emancipation. Empowerment. Professional qualification.

\section{Introdução}

Ainda que a mulher tenha obtido relevantes conquistas na luta por igualdade de direitos entre homens e mulheres, as mulheres em nosso país ainda sofrem abusos incessantes e perdas e danos, tanto no ambiente familiar como no mundo da educação e do trabalho.

Embora as mulheres passem a ocupar lugar de fala na ciência, na economia, na política, nas artes, na indústria, nos movimentos sociais e na comunicação, por meio de lutas em favor da construção de políticas públicas específicas para assegurar seus direitos e compensar as desvantagens enfrentadas na sociedade marcadamente machista em que vivemos, muitas desigualdades persistem e pressionam por políticas de apoio que contribuam para que as mulheres, sobretudo aquelas com baixa escolaridade, possam construir melhores condições de vida para si e suas famílias.

A formação para emancipação e geração de renda das mulheres se faz necessária para que as instituições de ensino ofereçam uma formação que impulsione significativa mudança de qualidade de vida para mulheres em situação de vulnerabilidade social, de forma que elas superem lacunas de conhecimentos estruturais e recebam qualificação profissional que facilite sua inserção no mercado de trabalho e obtenham assim remuneração adequada para seu sustento.

A taxa de participação para o total da população ocupada se mostrou relativamente estável ao longo dos cinco anos para o total da população, mas teve relativo incremento para as mulheres, passando de 52,5\%, em 2012, para 53,7\%, em 2016. Historicamente os homens registram maior engajamento na atividade laboral, sendo mais elevado nas duas faixas etárias intermediárias, que compreendem as idades de 30 aos 59 anos.

Nos municípios do estado de São Paulo, a realidade de trabalho e remuneração das mulheres acompanha uma realidade conhecida no país, em que o mercado de trabalho ainda remunera melhor o trabalhador homem do que a trabalhadora mulher, no cumprimento da mesma função. Enquanto entre as categorias de cor ou raça a taxa de participação foi 
semelhante, em torno de $64,0 \%$, entre homens e mulheres ela foi bastante distinta, sendo inferior para a população feminina. Entretanto, neste curto período de cinco anos, o diferencial entre as taxas de homens e mulheres se reduziu, passando de 23,6 pontos percentuais, em 2012, para 21,7 pontos percentuais, em 2016. Este movimento está de acordo com a evolução histórica recente, em que se observa o crescimento da participação das mulheres no mercado de trabalho brasileiro (IBGE, 2014).

Os trabalhadores de cor preta ou parda também se inserem mais cedo no mercado de trabalho, quando comparados com os trabalhadores brancos, característica que ajuda a explicar sua maior participação em trabalhos informais. Entre as mulheres foi maior a participação daquelas que começaram a trabalhar com 15 anos ou mais de idade $(67,5 \%)$ quando comparadas com a dos homens $(55,0 \%)$. A inserção mais tardia das mulheres no mercado de trabalho pode estar relacionada tanto ao fato de elas terem maior escolaridade que os homens, quanto à maternidade e aos encargos com os cuidados e afazeres domésticos (IBGE, 2014).

O Sistema de Indicadores Sociais, publicado pelo IBGE já em 2016, mostra que as mulheres sem instrução ou com o ensino fundamental incompleto recebiam 20,6\% menos do que os homens de mesmo nível, proporção que se torna maior na medida em que aumenta o nível de instrução, chegando a 56,6\% entre os trabalhadores com nível de ensino superior ou acima. Entre os trabalhadores brancos e pretos ou pardos, observa-se comportamento um pouco distinto, com a redução dos diferenciais em favor dos trabalhadores brancos até o ensino médio completo e superior incompleto, quando volta a subir no nível seguinte. Entre os trabalhadores com nível superior ou mais, o diferencial alcança 45,5\% (IBGE, 2016).

$\mathrm{O}$ detalhamento regional por sexo mostra que, mesmo tendo crescido relativamente pouco, a taxa de desocupação das mulheres é superior à dos homens nacionalmente e em praticamente todas as Unidades Federativas (UF). Para os homens, 14 UFs registraram taxa de desocupação até $10,0 \%$, sendo cinco delas inferiores a 7,0\% e nenhuma superior a 14,0\%. Já para as mulheres, a maioria das UFs registrou taxas acima de $10,0 \%$, sendo que em oito delas a taxa superou os $14,0 \%$ enquanto nenhuma foi inferior a $7,0 \%$.

As relações de poder e as produções da Verdade e do Sujeito estão absolutamente entrelaçadas com as questões de gênero. Historicamente, as relações de poder se associam à dominação masculina, daí a relevância da crítica feminista à negligência de Foucault ao gênero na análise genealógica. Entendemos, conforme Butler (1986, 2000), que a discussão sobre a subjetividade deva se dar concomitantemente à problematização da identidade de gênero e dos regimes de verdade que a produzem - uma vez que as pessoas se constituem em 
sua subjetividade e em seus corpos ao adquirir seu gênero conforme padrões reconhecidos de inteligibilidade de gênero. Butler (2003, p. 11) irá problematizar a questão das identidades, do gênero, do corpo e do desejo na medida em que "Foucault revela uma indiferença problemática em relação à diferença sexual".

Para Foucault, a categoria sexo é produto de uma economia reguladora difusa da sexualidade que suprime a multiplicidade subversiva de uma sexualidade que rompe com as hegemonias heterossexual, reprodutiva e médico-jurídica. Entretanto, Foucault desperta dúvida sobre a natureza precisa das práticas regulatórias que produzem a categoria sexual. Foucault repreende a hipótese repressiva de se basear em um desejo original, afirmando que esse desejo é um efeito da própria lei coercitiva. Assim, ele entende que a sexualidade é sempre construída nos modos de subjetivação e, portanto, nas relações de conhecimento e poder.

Nos últimos anos, em consequência de diversos fatores, como a melhoria das condições sanitárias e de acesso a bens e serviços, as pessoas têm vivido mais tempo. Os avanços na área da saúde têm possibilitado que cada vez mais pessoas consigam viver por um período mais prolongado, mesmo possuindo algum tipo de incapacidade.

Uma pessoa nascida no Brasil em 2016 tinha expectativa de viver, em média, até os 75 anos, nove meses e sete dias (75,8 anos). Isso representa um aumento de três meses e 11 dias a mais do que para uma pessoa nascida em 2015. A expectativa de vida dos homens aumentou de 71,9 anos em 2015 para 72,2 anos em 2016, enquanto a das mulheres foi de 79,1 para 79,4 anos.

Em 1940, a expectativa de vida era de 45,5 anos, sendo 42,9 para homens e 48,3 anos para mulheres. Entre 1940 e 1960, o Brasil praticamente reduziu pela metade a taxa bruta de mortalidade (o número de óbitos de um ano dividido pela população total em julho daquele mesmo ano), caindo de 20,9 óbitos para cada mil habitantes para 9,8 por mil. A expectativa de vida ao nascer em 1960 era de 52,5 anos. Ao todo, a expectativa de vida aumentou 30,3 anos entre 1940 e 2016, chegando a 75,8 anos.

Em 1940, um indivíduo ao completar 50 anos tinha uma expectativa de vida de 19,1 anos, vivendo em média 69,1 anos. Com o declínio da mortalidade neste período, um mesmo indivíduo de 50 anos, em 2016, teria uma expectativa de vida de 30,3 anos, esperando viver em média até 80,3 anos, ou seja, 11,3 anos a mais do que um indivíduo da mesma idade em 1940

Fairclough (1997, p. 298), com precisão, declara: 
Heterogeneidade textual é a presença e trabalha através das contradições. Identidade, relações sociais e conhecimento estão textualmente enlaçados. $\mathrm{O}$ mundo, os sujeitos sociais, as relações sujeito-sujeito e as relações mundosujeito são todos construídos nos textos em modos contraditórios. Heterogeneidade textual é também, entretanto, a presença e, trabalhando através dos dilemas-modo de experiência e reação, tenta mover-se além dessas contradições. Textos são lugares para a luta social (FAIRCLOUGH, 1997, p. 298).

Em 2016, um homem de 20 anos tinha 4,5 vezes mais chances de não completar 25 anos do que uma mulher no mesmo grupo de idade. Este fenômeno pode ser explicado pela maior incidência dos óbitos por causas externas ou não naturais, que atingem com maior intensidade a população masculina. Em 1940, o fenômeno da sobre mortalidade masculina não era registrado no país, o que mostra que ele está relacionado com o processo de urbanização e metropolização do Brasil. A partir de 1980, as mortes associadas às causas externas ou não naturais, que incluem os homicídios, suicídios, acidentes de trânsito, afogamentos, quedas acidentais etc. passaram a desempenhar um papel de destaque, de forma negativa, sobre a estrutura por idade das taxas de mortalidade, particularmente dos adultos jovens do sexo masculino.

Além disso, as mulheres ocupam o espaço periférico enquanto aos homens ocupam espaços mais centrais, zonas industriais e zonas comerciais. A figura feminina é vista como um espaço vazio. Nas práticas discursivas comerciais, as mulheres devem ser preenchidas pelo consumo, posicionando-se no discurso apenas como compradoras. Como áreas de reprodução biológica, os corpos femininos são representados como corpos vazios, necessitando de cuidados enquanto esperam ser preenchidos para a maternidade. Nos relacionamentos afetivos, a mulher deve permanecer dentro de casa e seu papel é o de guardiã passiva do bem-estar masculino.

Hofstede (1991) declara:

Quando os homens estão juntos, a cultura masculina tem tendência a predominar, no inverso, a cultura feminina domina quando as mulheres estão reunidas. Dar a estas diferenças o nome de "culturas" acentua a sua natureza profunda a emocional. A cultura feminina é alheia à maior parte dos homens e o inverso também é verdadeiro. O contato com uma cultura estranha desencadeia muitas vezes um choque cultura, que constitui uma reação visceral irracional. As outras culturas parecem-nos por vezes à primeira vista ridículas, inquietantes ou equivocadas. Este tipo de sensação pode existir entre os sexos no interior de uma mesma sociedade. Em quase todas as sociedades, os homens dominam a vida política, a vida social e o mundo dos negócios. (HOFSTEDE, 1991, p. 106) 
Entre 1940 e 2016 também diminuiu a mortalidade feminina no período reprodutivo, de 15 a 49 anos de idade. Em 1940, de cada cem mil nascidas vivas, 57.336 completaram 45 anos. Já em 2016, de cada cem mil nascidas vivas 98.367 atingiram os 15 anos de idade, e destas 94.208 chegaram ao final deste período. Logo, a probabilidade de uma recém-nascida completar o período fértil em 1940, que era de 573\% passou para 942\% em 2016.

\section{A Educação Profissional no Brasil}

No Brasil, historicamente a educação profissional atendeu aos objetivos do mercado de trabalho e sempre foi vista de maneira preconceituosa em decorrência de sua herança colonial e escravista em que o trabalho manual era reservado aos negros e subservientes.

No período colonial o modo de produção não exigia pessoal qualificado e, portanto, inexiste a oferta de educação para as classes trabalhadoras. Foi com o processo de industrialização que se verifica os primeiros esforços governamentais no sentido de oferecimento de ensino profissional, relegado sempre à classe social desfavorecida, que necessitava ingressar no mercado de trabalho precocemente (MOURA, 2010).

Nos últimos anos, o conceito de educação profissional vem se ampliando, para uma compreensão que ultrapassa a mera formação e preparação para uma profissão ou mercado de trabalho, mas que inclui conhecimentos teóricos e práticos, científicos e tecnológicos, que adota o conceito de trabalho como princípio educativo e a cultura técnica articulada à cultura geral.

Em uma sociedade de base patriarcal, como a nossa, o processo de educação voltado para as mulheres geralmente esteve atrelado à papéis sociais atribuídos, determinados em bases biológicas que são de extrema importância: desempenham na história da mulher um papel de primeiro plano, são um elemento essencial de sua situação.

[...] Sendo o corpo o instrumento de nosso domínio do mundo, este se apresenta de modo inteiramente diferente segundo seja apreendido de uma maneira ou de outra. Eis por que os estudamos tão demoradamente; são chaves que permitem compreender a mulher. Mas o que recusamos é a ideia de que constituem um destino imutável para ela. Não bastam para definir uma hierarquia dos sexos; não explicam por que a mulher é o Outro; não a condenam a conservar para sempre essa condição subordinada (BEAUVOIR, 1980, p. 52)

Neste sentido, a educação profissional visa, além da inclusão do aluno no mercado de trabalho, proporcionar uma ampla formação cidadã, que possibilite sua emancipação, inclusão e atuação ativa na sociedade. Uma formação cidadã, que para além da empregabilidade e 
treinamento para o mercado de trabalho, inclui saberes e habilidades que possibilitem ao aluno a ampliação de sua leitura do mundo e uma efetiva participação social (BRASIL, 2007).

A Educação Profissional e Tecnológica tem pelo menos duas dimensões importantes, que são a dimensão da inclusão e também a da emancipação, na medida em que não apenas inclui a pessoa numa sociedade desigual, mas lhe dá as ferramentas necessárias para que ela construa o seu itinerário de vida, possa se emancipar e se constituir como cidadã (PACHECO, 2011, p. 5).

Por outro lado, o ensino profissionalizante deve atender também a demandas por qualificação e requalificação profissional da população adulta de baixa escolaridade, excluídos da educação regular, por intermédio de uma rede específica de cursos de curta duração, visando à formação inicial e continuada do trabalhador.

É relevante registrar que o enfrentamento da situação de desigualdade social experimentado em nosso país se faz com a compreensão de que o modo de produção capitalista, em que se baseia nossa economia e sociedade, sustenta-se na exploração do trabalho e acumulação de riquezas pelos detentores do capital e dos meios de produção.

Desta forma, para a manutenção do sistema e do acúmulo de riquezas, historicamente, uma parcela da população é sistematicamente excluída. Segundo Saffioti (2013), intelectual feminista pioneira ao analisar a condição da mulher numa perspectiva de classes, a força de trabalho feminina é especialmente alijada do sistema. A autora discute os mitos que mantêm historicamente a mulher em uma condição subalterna e que se reelabora com o passar do tempo.

Referente ao período da chamada Revolução Industrial, por exemplo, aponta que:

O modo capitalista de produção não faz apenas explicitar a natureza dos fatores que promovem a divisão da sociedade em classes sociais; lança mão da tradição para justificar a marginalização efetiva ou potencial de certos setores da população do sistema produtivo de bens e serviços. Assim é que o sexo, fator de há muito selecionado como fonte de inferiorização social da mulher, passa a interferir de modo positivo para a atualização da sociedade competitiva, na constituição das classes sociais. (...) Aparentemente, no entanto, são as deficiências físicas e mentais dos membros da categoria sexo feminino que determinam a imperfeição das realizações empíricas das sociedades competitivas. A mulher faz, portanto, a figura de elemento obstrutor do desenvolvimento social, quando, na verdade, é a sociedade que coloca obstáculos à realização plena da mulher. (SAFFIOTI, 2013, p. 66)

As reflexões da autora, lapidares para as lutas das mulheres, fundamentam uma perspectiva crítica sobre a condição atual da mulher no mundo do trabalho. 
A prefeitura Municipal de Araraquara oferece projetos por meio de edital que traz como referência de discussão na temática do empoderamento o texto da ONU Mulheres. Constituem-se como um conjunto de considerações que ajudam a comunidade empresarial a incorporar em seus negócios valores e práticas que visem à equidade de gênero e ao empoderamento de mulheres.

Os sete princípios de Empoderamento das Mulheres definidos são: Estabelecer liderança corporativa sensível à igualdade de gênero, no mais alto nível; Tratar todas as mulheres e homens de forma justa no trabalho, respeitando e apoiando os direitos humanos e a não-discriminação; Garantir a saúde, segurança e bem-estar de todas as mulheres e homens que trabalham na empresa; Promover educação, capacitação e desenvolvimento profissional para as mulheres; Apoiar empreendedorismo de mulheres e promover políticas de empoderamento das mulheres através das cadeias de suprimentos e marketing; Promover a igualdade de gênero através de iniciativas voltadas à comunidade e ao ativismo social; Medir, documentar e publicar os progressos da empresa na promoção da igualdade de gênero, para mulheres para atividades com o fomentar a reflexão, o diálogo e a conscientização sobre a condição das mulheres na sociedade atual.

Outro projeto realizado pela secretaria Municipal da Cultura e Fundart, "Belas, Recatadas e do Lar", são quatro mulheres que trabalham durante o dia, cuidam de suas próprias casas e ainda cantam na noite araraquarense. Algumas são casadas, com filhos e cuidam de suas famílias sem esquecer seus ideais. Neste show, as artistas abordam o empoderamento feminino e todos os demais direitos da mulher moderna, o que para elas, não combina com o termo "bela, recatada e do lar", e daí a ironia no título deste show que aponta a luta da mulher contra os padrões de antigamente, quando a submissão era uma regra préestabelecida para a mulher.

Sendo o empoderamento feminino o ato de conceder o poder de participação social às mulheres, garantindo que possam estar cientes sobre a luta pelos seus direitos, como a total igualdade entre os gêneros, também conhecido como empoderamento das mulheres, esta ação consiste no posicionamento das mulheres em todos os campos sociais, políticos e econômicos, defendem. Pensando nisso, as cantoras produziram este projeto musical para protestar de forma musical e com muito bom humor, sobre o termo "bela, recatada e do lar" que vai na contramão daquilo pelo qual as artistas lutam. "Nesse projeto criativo escolheram músicas consagradas da MPB cujas letras batem de frente com esse conceito ultrapassado. Protestam, vale destacar, contra a narrativa de um "Manual da Boa Esposa", originado na década de 50. 
A partir das orientações desse manual, as cantoras conduzem os diálogos em palco e o repertório. No show, as cantoras se apresentam acompanhadas pelos músicos.

No campus de Araraquara do IFSP também são desenvolvidos projetos nesse sentido. O projeto "Saber cuidar: formação cidadã para autonomia e geração de renda para mulheres" oferece o curso de cuidadora de idosos, para mulheres com idades entre 18 e 55 anos, incluindo a inserção de várias alunas no mercado de trabalho e a matrícula de algumas alunas em cursos superiores de enfermagem, para dar continuidade aos estudos.

O Programa "Mulheres do IFSP" foi criado em 2016 com o objetivo de dar continuidade às ações do "Programa Mulheres Mil" realizado pelo Instituto entre 2012 e 2014. A variedade de atividades de confecção de bonecas de pano à manutenção predial, visase além da qualificação profissional, o resgate da autoestima e à inclusão socioprodutiva de mulheres, cis e transgênero, submetidas ao processo de exclusão social.

Compreende-se que a transexualidade traz algumas barreiras para a inserção das pessoas trans. ao mercado de trabalho, como por exemplo a legalização de seus nomes sociais e terminar os estudos que lhes permitirão seguir a carreira que almejam. Ainda no que tange às suas inserções no mundo do trabalho, Nascimento (2003) faz a seguinte afirmação:

As possibilidades de inserção no mercado de trabalho para as transgêneros são mínimas; mesmo nas situações em que estas executem atividades tidas como femininas, não são consideradas mulheres e pela ambiguidade são alvos de preconceitos por parte da sociedade. Considera-se que a questão da diversidade é colocada a dupla dificuldade enfrentada pelas transgêneros, pois é difícil para a mulher entrar no mercado de trabalho e ter as mesmas condições trabalhistas e salariais do homem, o desafio aumenta para a travesti. (NASCIMENTO, 2003, p. 37).

Os campi de Boituva e Matão oferecem o curso de agricultura familiar de base agroecológica por meio dos projetos "Qualificação profissional de agricultoras familiares" e "Mulheres rurais e agroecologia nos assentamentos Monte Alegre e Bela Vista do Chibarro: formação para a autonomia econômica", respectivamente.

O curso de artesã de bonecas de pano foi o escolhido pelo campus São João da Boa Vista, enquanto que, em Votuporanga, o projeto "Mulheril Manutenções" oferece o curso de auxiliar de manutenção predial. Os projetos, todos com duração de cinco meses, foram realizados no segundo semestre de 2017.

No campus Matão, as atividades com mulheres rurais são realizadas desde 2014 em parceria com a Prefeitura de Araraquara por meio do Núcleo de Estudos em Agroecologia, com objetivo de capacitar as mulheres que trabalham no campo e vendem seus produtos nas 
feiras livres. Desde então, já foram atendidas mulheres de Matão, Araraquara, Ribeirão Preto e Vale do Ribeira, entre elas quilombolas e indígenas.

Os projetos voltados à formação cidadã e à qualificação profissional de mulheres maiores de 16 anos, em situação de vulnerabilidade social, são oferecidos por meio do Edital $n^{\circ}$ 824/2016, da Pró-reitoria de Extensão. As alunas são selecionadas pelo campus com o apoio de instituições parceiras, como ONGs, lideranças locais e centros de referência de assistência social. No campus São João da Boa Vista, o Mulheres do IFSP prioriza a formação das mães dos estudantes.

De acordo com o pró-reitor de Extensão, Wilson de Andrade Matos, ressalta que é importante que a Instituição invista em ações voltadas aos grupos mais vulneráveis da sociedade. "Vivemos em uma sociedade machista, em um contexto em que o feminicídio é uma realidade. $\mathrm{O}$ empoderamento feminino só pode se estabelecer no coletivo, por isso pensamos em projetos que trabalham com o coletivo de mulheres, propiciando espaços em que elas possam partilhar suas experiências e conquistar juntas um espaço na sociedade por meio do trabalho, garantindo, assim, uma emancipação por meio da geração de renda." (IFSP, 2017).

Observa-se que persiste o grave problema de valorização do trabalho da mulher no campo, que reflete diretamente na família e na sociedade. Para vencer esse cenário, a formação tem como meta o empoderamento subjetivo da mulher por meio da elevação da autoestima e da autonomia econômica e profissional.

Observou-se que o processo de empoderamento ocorreu em todas as fases de luta pela terra e continua ocorrendo, tanto no espaço público quanto no espaço privado, exigindo das mulheres cada vez mais capacitação, persistência e sofisticação no processo de aprendizagem técnica e política.

De acordo com Bourdieu (2007), empoderamento consiste na autonomia e na posição de dominador simultâneo num mesmo indivíduo. Por exemplo, em uma empresa, existe um cargo de gerência e o ocupante tem o poder formal. A partir desse cargo, ele pode se empoderar, aderindo às funções e à autonomia nas tomadas de decisões para si. Nesse sentido, pode-se dizer que há um processo de empoderamento, ou seja, o ocupante do cargo está se sentindo empoderado de fato.

Mosadale (2005) salienta que o empoderamento somente pode ser alcançado pelo indivíduo que quer se empoderar. Mesmo que um terceiro indivíduo possa criar uma situação ou condição favorável para que isso se concretize, somente o interessado pode realizar a ação. Portanto, todos os sinônimos e os significados da palavra empoderamento apresentam a 
capacidade de o indivíduo ter autonomia e controle nas suas ações e iniciativas, assumindo seu próprio destino.

Como ressalta Bakthin (1987, p. 174), durante as festas populares, não há espectadores ou convidados, todos e todas são sujeitos no ato de festejar. A hierarquia é abolida, o que abre possibilidades às pessoas; "o rito atribui o direito de gozar de certa liberdade, de empregar certa familiaridade, o direito de violar regras habituais da vida em sociedade".

Mesmo que a violação das regras não seja no total sentido de ruptura e sim, uma possibilidade simbólica, como a que torna possível, por algumas horas, ser rei. Desse modo, os ritos e as máscaras retiram o festejar do sentido único e fenômeno simples, ele pode se tecer de críticas e visão de mundo.

\section{A concepção das políticas públicas pela ótica da ação pública na educação}

Numa sociedade extremamente desigual e heterogênea a política educacional deve desempenhar um papel importante e ao mesmo tempo, no que diz respeito à democratização da estrutura ocupacional estabelecida, e a formação do cidadão, o assunto além de ser significativo do que torná-lo competitivo com o mercado global e globalizado.

A política e a política educacional, precisa conquistar maior eficácia em processos como de aprendizagem, gestão escolar e a aplicação de recursos, que são cada vez mais parcos e insuficientes e para caracterizar uma mudança a função política deste setor. Os atores na tomada de decisões, planejamento e na implementação da política de educação, alcançariam resultados positivos, no que se refere à avaliação dos resultados dos programas de política educacional, mais sobre a avaliação da política educacional.

Lemes (2016) aborda que no limite temos necessidade de compreender a política pública para a educação como aquelas ações que regulam e orientamos sistemas de ensino, instituindo, regulando e orientando, também, a educação escolar. Assim, podemos afirmar que políticas públicas educacionais dizem respeito à educação escolar. A educação só é escolar quando delimitada por um sistema, resultado dessas políticas estabelecidas e devidamente reguladas.

$\mathrm{O}$ autor refere-se ainda que o processo de decisão política, em sua lógica de desenvolvimento e articulação, se apresenta tal como o tipo de conhecimento que o legitima. Deve estar contido em uma lógica discursiva legitimadora e o instrumento regulador é caracterizado por quatro componentes: credibilidade, maleabilidade, relevância simbólica e pertinência; estas lhe outorgam valor e força, científica e política, que contribuem sensivelmente para a sua afirmação e penetração na sociedade. 
A complexidade que envolve o uma política que envolve as diferentes esferas da vida pública com entidades da sociedade civil. Também requer uma política social voltada para superar o caráter descontínuo que tem caracterizado as políticas públicas no Brasil.

Concluiu-se que um conflito de gênero decorre do conflito com o dominado a sociedade, que usa esse mecanismo para manutenção da ordem erigida culturalmente, sem posições cotidianas, a mulher em posição inferior, esta situação representa uma violação dos direitos humanos, principalmente, direito à igualdade entre homens e mulheres. Uma mulher em situação de violência está em um relacionamento onde uma submissão ao homem é predominante, na qual há preconceito à sua integridade física, psicológica e moral.

Face a violência contra a mulher, políticas públicas necessárias a respeitar a igualdade nas relações entre homens e mulheres e consolidar a cidadania, com ações que garantem espaço para denúncia, proteção e apoio mulheres vítimas de violência. A ação deve ser preço juntos para o confronto, prevenção, combate, assistência e garantia do problema da diversidade de áreas relevantes como saúde, educação, segurança pública, cultura, justiça, para levar em conta a complexidade da violência contra as mulheres.

É necessário usar a atenção da rede de suporte de forma articulada para garantir a assistência completa às mulheres e também é essencial que os agentes que compõem essa rede de capacidades no domínio da violência contra as mulheres, em especial, entendam melhor do fenômeno e assim fornecer uma melhor assistência às vítimas.

Desta forma, a rede contra a violência de gênero poderá desempenhar um papel importante na luta nacional e ter uma resposta eficaz a este tipo de violência, que contribui para a consolidação da cidadania das mulheres e colabora na construção de uma sociedade em que homens e mulheres são iguais e a violência contra a mulher é tratada com seriedade e devida reprimida.

Segundo Saffioti (2004) o patriarcado refere-se ao sistema social no qual o homem é o ator fundamental da organização social, utilizando da sua autoridade, o poder de macho, sobre as mulheres e os filhos. O patriarcado representa o regime da dominação-exploração das mulheres pelos homens como as mulheres se responsabilizam no comando e direção dos filhos e trabalho doméstico, enquanto os homens nascem com a responsabilidade de apoiar a família. A divisão predominante do trabalho entre homens e mulheres levou homens e mulheres a assumirem posições desiguais em termos de poder, prestígio e riqueza.

Desta forma, homens e mulheres ao longo dos anos uma organização social de restrição já hierárquica e que contém violência, eles ocuparam posições desiguais na sociedade. Essa desigualdade é o resultado de uma construção social que determina, através 
da separação sexual de papéis, as áreas em que as mulheres atuam e outras em que os homens podem atuar.

\section{Considerações finais}

Uma das barreiras que as travestis e transexuais enfrentam ao entrar no mundo do trabalho é que elas são socialmente identificáveis, ou seja, muitas empresas ainda resistem ao reconhecimento da identidade de gênero e nome social adotado pela pessoa trans, e quando no caso de entrevistas, eles escolhem chamar pelo seu nome civil. Isso mostra que algumas organizações ainda não estão preparadas para lidar com a diversidade. Ressalta-se que teoria e prática não se limitam a tal abordagem, e também é possível estabelecer um paralelo entre elas.

Bruschini (2007) e Amaral (2012) defendem que o aumento da inserção feminina no mercado de trabalho foi possível, inclusive, pelo ingresso nas universidades e pela expansão da escolaridade das mulheres, uma vez que elas estão liderando os índices de escolaridade em relação aos homens. De acordo com Bruschini (2007) e Pruppin (2004), com o aumento do grau de instrução das mulheres, além de continuar marcando presença em espaços tradicionais de ocupação feminina, como o magistério e a enfermagem, elas têm adentrado também e, áreas profissionais de prestígio.

A carreira profissional das mulheres não tem sido linear e silenciosa. Mesmo hoje, sua inserção no mercado exige um grande esforço diante dos obstáculos existentes. Embora o nível de educação seja superior ao dos homens, as mulheres ainda ganham salários mais baixos que os homens e ocupam posições mais baixas. Mesmo com uma expansão significante do trabalho feminino no mundo do trabalho, a participação masculina é mais importante e importante, em particular no caso dos postos de direção.

Embora certas leis que garantem a igualdade de gênero no mercado de trabalho, tais como aquelas contidas na Constituição de 1988, não sejam cumpridas, elas não devem ser conscientizadas da igualdade de gênero, acompanhadas por uma quebra de preconceitos. contra as mulheres.

As condições que podem limitá-las, são os obstáculos culturais que devem ser discutidos e eliminados, especialmente os relacionados à gestão doméstica: presume-se que sejam obrigações complementares que devem ser divididas (igualmente) entre o casal e incluir os filhos. 
Dada a realidade, acredita-se que os empregadores e as empresas podem e devem adotar políticas inclusivas, proporcionando uma oportunidade justa para as mulheres ocuparem posições de responsabilidade e garantindo a igualdade salarial no exercício de funções iguais. para aqueles dos homens.

\section{REFERÊNCIAS}

AMARAL, G. A. Os desafios da inserção da mulher no mercado de trabalho. Itinerarius Reflectionis. Revista eletrônica do curso de pedagogia do campus Jataí, Universidade Federal de Goiás - UFG, Jataí, v. 8, n. 2, p. 1-20, 2012.

BAKHTIN, M. A cultura popular na Idade Média e no Renascimento: o contexto de François Rabelais. São Paulo/Brasília: HUCITEC/Editora Universidade de Brasília, 1987.

BEAUVOIR, S. O Segundo Sexo, v. I, II. Tradução de Sérgio Milliet. Rio de Janeiro: Nova Fronteira, 1980.

BRASIL. Ministério da Educação. PROEJA. Formação Inicial e Continuada/Ensino Fundamental. Documento Base. SETEC, Brasília: Ministério da Educação, 2007. Disponível em: http://portal.mec.gov.br/setec/arquivos/pdf2/proeja_fundamental_ok.pdf. Acesso em: 07 fev. 2017.

BRASIL. Ministério da Saúde. Guia prático do cuidador. Brasília: Secretaria de Gestão do Trabalho e da Educação na Saúde, 2008.

BRASIL. Plano Nacional de Políticas para as Mulheres. Brasília: Secretaria de Políticas para as Mulheres, 2013.

BRASIL. Ministério da Educação. Guia da Metodologia de Acesso, Permanência e Êxito do Mulheres Mil. Disponível em: http://prx.ifsp.edu.br/images/pdf/Guia_metodologico.pdf. Acesso em: 20 nov 2018.

BOURDIEU, P. A dominação masculina. 5 ed. Rio de Janeiro: Bertrand Brasil, 2007.

BUTLER, J. Variações sobre sexo e gênero: Beauvoir, Witting e Foucault. In: BENHABIB, S.; CORNELL, D. (Orgs.). Feminismo como crítica da modernidade. Rio de Janeiro: Rosa dos Tempos, 1986.

BUTLER, J. Subjection, resistence and resignification. In: BUTLER, J. The psychic life of power: Theories in subjections. California: Standford University Press, 2000.

BUTLER, J. Problemas de gênero: Feminismo e subversão da identidade. Rio de Janeiro: Civilização Brasileira, 2003.

BRUSCHINI, C.; PUPPIN, A. B. Trabalho de mulheres executivas no Brasil no final do século XX. Cadernos de Pesquisa, São Paulo, v. 34, n. 121, p. 105-138, jan/abr, 2004. 
CENTRAL ÚNICA DOS TRABALHADORES (CUT). Igualdade de remuneração entre homens e mulheres - Experiências e desafios. São Paulo: Central Única dos Trabalhadores/SNMT, 2010.

FAIRCLOUGH, N. Critical discourse analysis in the 1990s: challenges and responses. In: PEDRO, E. R. (org.) Discourse Analysis Proceedings of the 1st Internacional Conference On Discourse Analysis. Lisboa: Colibri, 1997.

HOFSTEDE, G. Culture's Consequences: International differences in work related values. Beverly Hills: Sage, 1980.

INSTITUTO BRASILEIRO DE GEOGRAFIA E ESTATÍSTICA (IBGE). Censo Demográfico de 2010. Rio de Janeiro, 2010.

INSTITUTO BRASILEIRO DE GEOGRAFIA E ESTATÍSTICA (IBGE). Sistema de Indicadores Sociais. Rio de Janeiro, 2016.

INSTITUTO FEDERAL DE EDUCAÇÃO, CIÊNCIA E TECNOLOGIA DE SÃO PAULO (IFSP). Programa Mulheres do IFSP atende a cem alunas. Disponível em:

http://www2.ifsp.edu.br/index.php/outras-noticias/52-reitoria/4762-programa-mulheres-mildo-ifsp-atende-a-cem-alunas.html. Acesso em: 12 nov. 2018.

LEMES, S. S. Indagações sobre as políticas educacionais e reflexões sobre demandas percebidas pelo Estado brasileiro: tópicos para análise circunstanciada de seus instrumentos de ação. Revista Ibero-Americana de Estudos em Educação, v. 11, p. 1616-1625, 2016.

MINAYO, M. C. S. Visão antropológica do envelhecimento humano. In: MINAYO, M. C. S. Velhices, reflexões contemporâneas. São Paulo: SESC PUC, 2006.

MOSEDALE, S. Assessing women's empowerment: towards a conceptual framework. Journal of International Development, v. 17, n. 2, p. 243-257, 2005.

MOURA, D. H. A relação entre a educação profissional e a educação básica na CONAE 2010: possibilidades e limites para a construção do novo plano nacional de educação.

Educação \& Sociedade, Campinas, v.31, n. 112, p. 875-894, jul.-set. 2010.

NASCIMENTO, E. S; LARA, S. V. Alternativas de mercado de trabalho para as travestis de Aracaju. Aracaju: Ministério da Justiça, 2003.

PACHECO, E. Mulheres Mil na Rede Federal: caminhos da inclusão. Página do Programa Mulheres Mil. 2011.

SAFFIOTI, H. I. B. A mulher na sociedade de classes: mito e realidade. Petrópolis: Editora Vozes, 1976. 


\section{Como referenciar este artigo}

MONTEIRO, Solange Aparecida de Souza. Empoderamento feminino e a formação cidadã para a emancipação da mulher. Revista on line de Política e Gestão Educacional, Araraquara, v. 22, n. 3, p. 1182-1197, set./dez., 2018. E-ISSN:1519-9029. DOI: 10.22633/rpge.v22i3.12018

Submetido em: 15/04/2018

Aprovado em: 25/08/2019 